\title{
Assessment of antibiotic resistance in starter and non-starter lactobacilli of food origin
}

\author{
Marta Dušková1,2, Monika Morávková1, Jakub Mrázek², Martina Florianová1, \\ Lenka Vorlová ${ }^{2}$, Renáta Karpíšková ${ }^{1,2}$ \\ ${ }^{1}$ Veterinary Research Institute, Brno, Czech Republic \\ ${ }^{2}$ University of Veterinary and Pharmaceutical Sciences Brno, Faculty of Veterinary Hygiene and Ecology, \\ Department of Animal Origin Food and Gastronomic Sciences, Brno, Czech Republic \\ ${ }^{3}$ Czech Academy of Sciences, Institute of Animal Physiology and Genetics, Prague, Czech Republic
}

Received June 1, 2020

Accepted December 21, 2020

\begin{abstract}
The absence of acquired resistance to antimicrobials has become an important criterion in evaluation of the biosafety of lactobacilli used as industrial starter or probiotic cultures. The aim of this study was to assess antibiotic resistance in starter and non-starter lactobacilli of food origin. Minimal inhibitory concentrations of ampicillin, chloramphenicol, clindamycin, erythromycin, gentamicin, kanamycin, streptomycin, tetracycline and vancomycin were established in 81 strains of lactobacilli (L. acidophilus, L. animalis, L. brevis, L. curvatus, L. delbrueckii, L. fermentum, L. helveticus, L. paracasei, L. plantarum, L. rhamnosus and L. sakei) by the microdilution method. The strains were classified as susceptible or resistant to antimicrobials based on the cut-off values according to the EFSA guideline. Sixty-two strains (77\% food isolates, 76\% starter or adjunct cultures) were resistant to at least one antimicrobial agent (the most frequently to aminoglycosides). Adjunct cultures showed a higher antibiotic resistance $(80 \%)$ than starters $(60 \%)$. Four multiresistant strains (3 food isolates, 1 adjunct culture) were analyzed by whole genome sequencing. One potentially transferable aad $\mathrm{E}$ gene (responsible for streptomycin resistance) was detected only in one multi-drug resistant strain of $L$. animalis originating from an adjunct culture. Thus, there is a risk of horizontal transmission of this gene. It is necessary to eliminate such strains from use in the food industry. This study provides relevant data concerning the use of lactobacilli in safe food production. To ensure food safety, detailed characterization of resistance to antimicrobials is necessary not only in starter strains but also in non-starter lactic acid bacteria isolated from food products.
\end{abstract}

Broth microdilution method, minimal inhibitory concentration, antimicrobial susceptibility, aadE gene

The emergence of antibiotic-resistant microbiota is a worldwide problem primarily caused by inappropriate and excessive use of antimicrobials in veterinary and human medicine and as growth promoters in farm animals (Bernardeau et al. 2008; Bardon et al. 2018). The development of bacterial resistance to antimicrobial agents is an increasing problem for public health. It affects not only the treatment in the human and veterinary medicine sector but it also influences the production and quality of food (Ammor et al. 2008; Verraes et al. 2013). The food chain constitutes one of the routes of spreading antibiotic resistance (Mathur and Singh 2005; Nawaz et al. 2011). Antimicrobialresistant bacteria may be found in soil, water and in samples of animal or human origin. Food products of animal origin may contain resistant microorganisms due to faecal contamination during the slaughter and meat processing. Products of plant origin may be contaminated during their production, e.g. by contaminated irrigation water, untreated manure or other sewage discharges. Furthermore, microbiota added during food processing as a starter culture, probiotics and bioconserving microbiota may act as reservoirs of transmissible genes of antibiotic resistance. There is also the possibility of cross-contamination with antimicrobial-resistant microbiota during food processing. As a consequence, transfer of

Address for correspondence:

Marta Dušková

Department of Animal Origin Food and Gastronomic Sciences

Faculty of Veterinary Hygiene and Ecology

University of Veterinary and Pharmaceutical Sciences Brno

Palackého tř. 1946/1, 61242 Brno, Czech Republic

Phone: +420541562720

E-mail: duskovam@vfu.cz

http://actavet.vfu.cz/ 
antibiotic resistance encoding genes between microorganisms after ingestion by humans may occur (Verraes et al. 2013).

Bacteria from the genus Lactobacillus are used as adjunct or starter cultures in the production of various fermented foods. A starter culture can be defined as a microbial suspension of large numbers of cells of at least one microorganism to be added to a pasteurized or raw food matrix intended for production of fermented food by steering and accelerating the fermentation process. These microorganisms cause rapid acidification of the raw material, production of organic acids, mainly lactic acid (Leroy and Vuyst 2004; Hati et al. 2013). Adjunct cultures are used for acceleration and intensification of flavour development in food products and for their probiotic characteristic (Ortigosa et al. 2006). In this way, they not only improve the texture and contribute to the acceptable sensory profile of the final product, but also enhance its microbial safety and shelf life. Lactobacilli are also able to colonize fermented food products and represent a predominant part of non-starter lactic acid bacteria (LAB) (Leroy and Vuyst 2004; Ortigo sa et al. 2006).

This genus with over 200 described species is characterized by high heterogeneity, which is reflected in its complex phylogeny (Abriouel et al. 2015). Lactobacilli reach the gastrointestinal tract via ingestion of a high number of representatives of this bacterial genus in the fermented food (typically $>8 \log \mathrm{CFU} / \mathrm{ml}$ ), where they interact with the resident gut microbiota of the host (Mathur and Singh 2005; Abriouel et al. 2015). However, some strains are able to carry antibiotic resistance genes and may be phenotypically resistant to antimicrobials. Some of them may even carry the mobile genetic elements containing the resistance genes and transfer them to other LAB or even to pathogens, thus threatening human health (Mathur and Singh 2005; Ammor et al. 2008; Toomey et al. 2010; Nawaz et al. 2011; Devirgiliis et al. 2013; Verraes et al. 2013; Rossi et al. 2014; Guo et al. 2017).

One possibility to reduce antibiotic resistance spread via food is testing the sensitivity of lactobacilli used in the food production to selected antibiotics. The European Food Safety Authority recommends that bacterial strains carrying mobile genetic elements containing the antibiotic resistance determinants should not be used in feeds, for the preparation of fermented products, and as probiotics. In 2018, the EFSA-FEEDAP Panel updated the criteria for the evaluation of antimicrobial resistance (AMR) in LAB. The established microbiological (epidemiological) breakpoints (cut-offs) facilitate the differentiation between resistant strains and strains susceptible to antimicrobials (EFSA 2018).

It is distinguished between two types of resistance, intrinsic (primary) and acquired (secondary). The primary resistance of bacteria to an antimicrobial agent is an integral, genetically determined component typical of this bacterial species. Intrinsic AMR is not considered to be of safety concern. In contrast, when a strain of a typically susceptible species is resistant to antimicrobial agent, it is considered to be acquired resistance (EFSA 2018). This resistance can be the result of either mutations in chromosomal genes or due to the acquisition of external genes from other bacteria. Mobile genetic elements that allow horizontal resistance gene transfer between microorganisms present the greatest risk factor in the spread of resistance (Mathur and Singh 2005; Nawaz et al. 2011; EFSA 2012, 2018). Identification of AMR genes is crucial to understanding the issue of resistance, for identification of resistant strains when genes are not or weakly expressed in vitro (Zankari et al. 2012). Therefore, the aim of this study was to assess the antibiotic resistance in starter and non-starter lactobacilli of food origin.

Bacterial strains

\section{Materials and Methods}

Susceptibility to antimicrobial agents was monitored in 81 lactobacilli of different species: L. acidophilus, L. animalis, L. brevis, L. curvatus, L. delbrueckii, L. fermentum, L. helveticus, L. paracasei, L. plantarum, L. rhamnosus and L. sakei (Table 1). The strains were identified based on the 16S rRNA gene sequencing 
(Ehrmann et al. 2003; Atashpaz et al. 2010; Yoon et al. 2017), polymerase chain reaction with genus- and species-specific primers and MALDI-TOF MS analysis in previous studies (Dušková et al. 2012). Twenty-five strains from starter or adjunct cultures and fifty-six strains originating from the collection of the Department of Animal Origin Food and Gastronomic Sciences (University of Veterinary and Pharmaceutical Sciences Brno) were isolated during routine analysis of fermented dairy products from retail, raw cow's milk and goat's colostrum $(n=39)$ obtained at the farm level, meat products and swab samples of semi-finished food products and the processing environment $(\mathrm{n}=17)$. Lactobacillus paracasei LMG12586 and Lactobacillus plantarum LMG6907, obtained from Belgian collections of microorganisms (LMG, Ghent, Belgium), were used as quality control strains for controlling the precision of susceptibility testing according to the ISO10932/IDF223 guideline (2010).

Antimicrobial susceptibility testing

Resistance/susceptibility to antimicrobials was determined using a broth microdilution method based on the international methodologies of the Clinical Laboratory Standards Institute (CLSI 2016), ISO10932/IDF223 guideline (2010) and the EFSA recommendations (2018). Bacterial cultures were tested on a microtitre plate with $100 \mathrm{ml}$ of LSM culture medium (90\% ISO-Sensitest broth $+10 \%$ MRS broth; Oxoid Ltd., Basingstoke, UK) with the addition of cysteine ( $0.3 \mathrm{~g}$ of cysteine per litre of medium, Sigma-Aldrich Corp., St. Louis, MO, U.S.A.). The following antimicrobials were tested: ampicillin (AMP; 0.125-16 $\mu \mathrm{g} / \mathrm{ml}$ ), streptomycin (STR; 2-256 $\mu \mathrm{g} / \mathrm{ml}$ ), tetracycline (TET; 0.5-64 $\mu \mathrm{g} / \mathrm{ml}$ ), erythromycin (ERY; 0.063-8 $\mu \mathrm{g} / \mathrm{ml}$ ), clindamycin (CLI; 0.063-8 $\mu \mathrm{g} / \mathrm{ml}$ ), chloramphenicol (CMP; 0.25-32 $\mu \mathrm{g} / \mathrm{ml}$ ), kanamycin (KAN; 0.5-2050 $\mu \mathrm{g} / \mathrm{ml})$, gentamicin (GEN; 0.125-512 $\mu \mathrm{g} / \mathrm{ml}$ ) and vancomycin (VAN; $0.25-32 \mu \mathrm{g} / \mathrm{ml})$. Microtitre plates inoculated with $5 \mu \mathrm{l}$ of the bacterial suspension with a McFarland standard turbidity of $1.2-1.3$ were incubated at $30^{\circ} \mathrm{C}$ (L. animalis, L. brevis, L. fermentum, L. plantarum, L. rhamnosus, L. sakei) or at $37{ }^{\circ} \mathrm{C}$ (L. acidophilus, L. curvatus, L. delbrueckii, L. helveticus, L. paracasei) over a period of $24 \mathrm{~h}$ under aerobic (L. paracasei, L. plantarum), anaerobic (L. acidophilus, L. animalis, L. delbrueckii, L. helveticus) or microaerophilic conditions (L. brevis, L. curvatus, L. fermentum, L. rhamnosus, L. sakei). The minimum inhibitory concentrations (MIC, $\mu \mathrm{g} / \mathrm{ml}$ ) were established. Based on the EFSA guidelines (2018), the strains were classified as susceptible or resistant. A tested strain was recorded to be resistant to an antibiotic, if its MIC value was higher than the reference cut-off value. If its MIC value was equal to or lower than the reference cut-off value, the strain was considered susceptible. A strain was considered as multidrug-resistant (MDR), if it was resistant to three or more antimicrobial groups. Each strain was tested repeatedly.

Whole genome sequencing analysis of bacterial strains

Based on the phenotypic results, four MDR strains were selected and subjected to whole genome sequencing (WGS) to determine firstly the acquired AMR genes. Total genomic DNA was extracted from the strains using cetyl trimethylammonium bromide (CTAB) according to Pavlik et al. (1999). Only high-quality DNA (A260/280 ratio of $\sim 1.8$ ) was used for the following analyses.

DNA libraries for whole genome sequencing were constructed using the NEBNext ${ }^{\circledR}$ Fast DNA LibraryPrep Set for Ion Torrent ${ }^{\mathrm{TM}}$ (New England Biolabs Inc., Ipswich, MA, U.S.A.) and quantified by a KAPA Library Quantification Kit (KAPA Biosystems Inc., UK). Whole-genome sequencing was performed using the Ion Torrent Proton platform (Thermo Fisher Scientific, Waltham, MA, U.S.A.) by the genome research company SEQme (Dobř́řs, Czech Republic). The analysis was conducted using Torrent Suite software, version 5.0.4. The reads were assembled and annotated by PATRIC, version 3.5.20 (Wattam et al. 2017). The presence of acquired antibiotic resistance genes was investigated using ResFinder, version 2.1 (Zankari et al. 2012) and CARD (Comprehensive Antibiotic Resistance Database; McArthur and Wright 2015).

\section{Results}

\section{Phenotypic profiles of antimicrobial resistances}

AMR testing of 81 lactobacilli is shown in Table 1. Only 19 of 81 tested strains (23.5\%) were susceptible to all antimicrobials tested. Sixty-two strains $(76.5 \%)$ were resistant to at least one antimicrobial agent. These strains and their phenotypes of resistance are listed in Table 2 .

\section{Identification of acquired antimicrobial resistance genes}

Four phenotypically determined MDR strains (3 food-derived strains of $L$. brevis, 1 adjunct culture of $L$. animalis) were analysed by whole genome sequencing. However, an antibiotic resistance determinant on a mobile element was confirmed in only one strain of L. animalis. Other genes of resistance to antibiotics could be located on the chromosome. In this strain originating from adjunct culture, aad $\mathrm{E}$ gene was detected on the mobile element using ResFinder. Also, the presence of ANT(6) gene in this strain was detected 


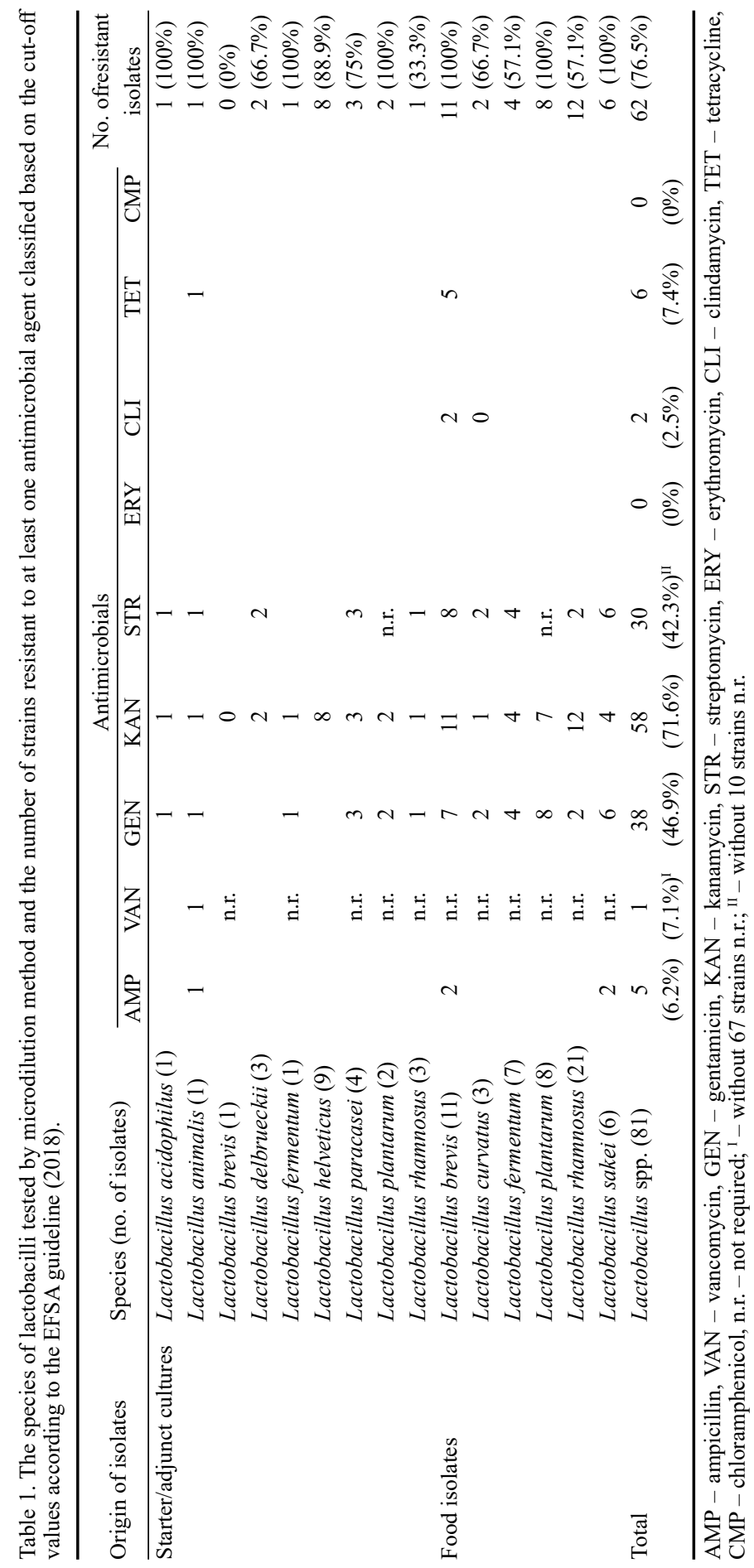


Table 2. Resistant lactobacilli classified based on the cut-off values according to the EFSA guideline (2018) and their phenotypes of resistance.

\begin{tabular}{|c|c|c|}
\hline Species & Strains & Phenotype of resistance, II \\
\hline Lactobacillus acidophilus & LBC 01 & $G E N-K A N-S T R$ \\
\hline Lactobacillus animalis & $\mathrm{LBC} 02 *$ & AMP-VAN-GEN-KAN-STR-TET \\
\hline \multirow[t]{8}{*}{ Lactobacillus brevis } & BIO I $44^{*}$, BIO III $62 *$ & $G E N-K A N-S T R$-CLI-TET \\
\hline & ML 438, BIO II 67 & $G E N-K A N-S T R$-TET \\
\hline & BIO II $72 *$ & AMP-KAN-STR-TET \\
\hline & ML 177, ML 71 & $G E N-K A N-S T R$ \\
\hline & ML 165 & $G E N-K A N$ \\
\hline & MLZ 334 & $K A N-S T R$ \\
\hline & ML 74 & AMP- $K A N$ \\
\hline & BIO II 60 & $K A N$ \\
\hline \multirow[t]{2}{*}{ Lactobacillus curvatus } & $\mathrm{C} 44$ & $G E N-K A N-S T R$ \\
\hline & KAS 575 & $G E N-S T R$ \\
\hline Lactobacillus delbrueckii & LBC 04, LBC 06 & $K A N-S T R$ \\
\hline Lactobacillus fermentum & $\begin{array}{l}\text { KAS } 578, \text { BIO II 57, BIO IV 14, } \\
\text { LBC } 07\end{array}$ & $\begin{array}{l}G E N-K A N-S T R \\
G E N-K A N\end{array}$ \\
\hline Lactobacillus helveticus & $\begin{array}{l}\text { LBC } 08, \text { LBC } 09, \text { LBC } 10, \text { LBC } 11, \\
\text { LBC } 13, \text { LBC } 14, \text { LBC } 15, \text { LBC } 16\end{array}$ & $K A N$ \\
\hline Lactobacillus paracasei & LBC 17, LBC 18, LBC 19 & $G E N-K A N-S T R$ \\
\hline \multirow[t]{2}{*}{ Lactobacillus plantarum } & $\begin{array}{l}\text { A } 54, \text { LBC } 21, \text { BIO I } 16, \text { C } 16, \text { C } 33 \text {, } \\
\text { D } 42, \text { KAS } 521, \text { KAS } 594, \text { LBC } 22\end{array}$ & $G E N-K A N$ \\
\hline & KAS 526 & $G E N$ \\
\hline \multirow[t]{4}{*}{ Lactobacillus rhamnosus } & BIO II 7, LBC 23 & $G E N-K A N-S T R$ \\
\hline & BIO III 25 & $G E N-K A N$ \\
\hline & BIO III 39 & $K A N-S T R$ \\
\hline & $\begin{array}{l}\text { BIO I 5, BIO II 5, BIO II 13, BIO II 15, } \\
\text { BIO III 15, BIO III 21, BIO IV } 2, \\
\text { BIO IV } 3, \text { BIO IV 4, }\end{array}$ & $K A N$ \\
\hline \multirow[t]{3}{*}{ Lactobacillus sakei } & KAS 1099, KAS 1105 & AMP-GEN-KAN-STR \\
\hline & KAS 881 , KAS 885 & $G E N-K A N-S T R$ \\
\hline & KAS 462, KAS 473 & $G E N-S T R$ \\
\hline
\end{tabular}

* Multidrug-resistant strain (resistant to at least three groups of antimicrobial agents); ${ }^{\mathrm{I}} \mathrm{AMP}-$ ampicillin, VAN - vancomycin, GEN - gentamicin, KAN - kanamycin, STR - streptomycin, CLI - clindamycin, TET - tetracycline; II in italics - antibiotics belonging to the same group (aminoglycosides)

by CARD. Based on the analysis of the surrounding aad $\mathrm{E}$ sequences in the studied strain, it has been found that a gene for the transposase is present (the transposase is part of the mobile elements and allows the transfer of genes present in these elements). Therefore, a risk of horizontal transmission of the $a a d \mathrm{E}$ gene exists. Based on these results, this strain may act as a reservoir of antibiotic resistance for other bacteria including the pathogenic ones.

\section{Resistance to antibiotics of lactobacilli based on origin of strains}

The least resistant strains were found in starter cultures where $40 \%$ of strains were susceptible to all tested antibiotics (Table 3). Adjunct cultures showed a higher percentage of resistance ( $80 \%$ of tested strains) than starter cultures ( $60 \%$ of tested strains). Yogurtderived strains, which were predominantly non-starter LAB or adjunct cultures, also showed almost $40 \%$ sensitivity to antibiotics. 


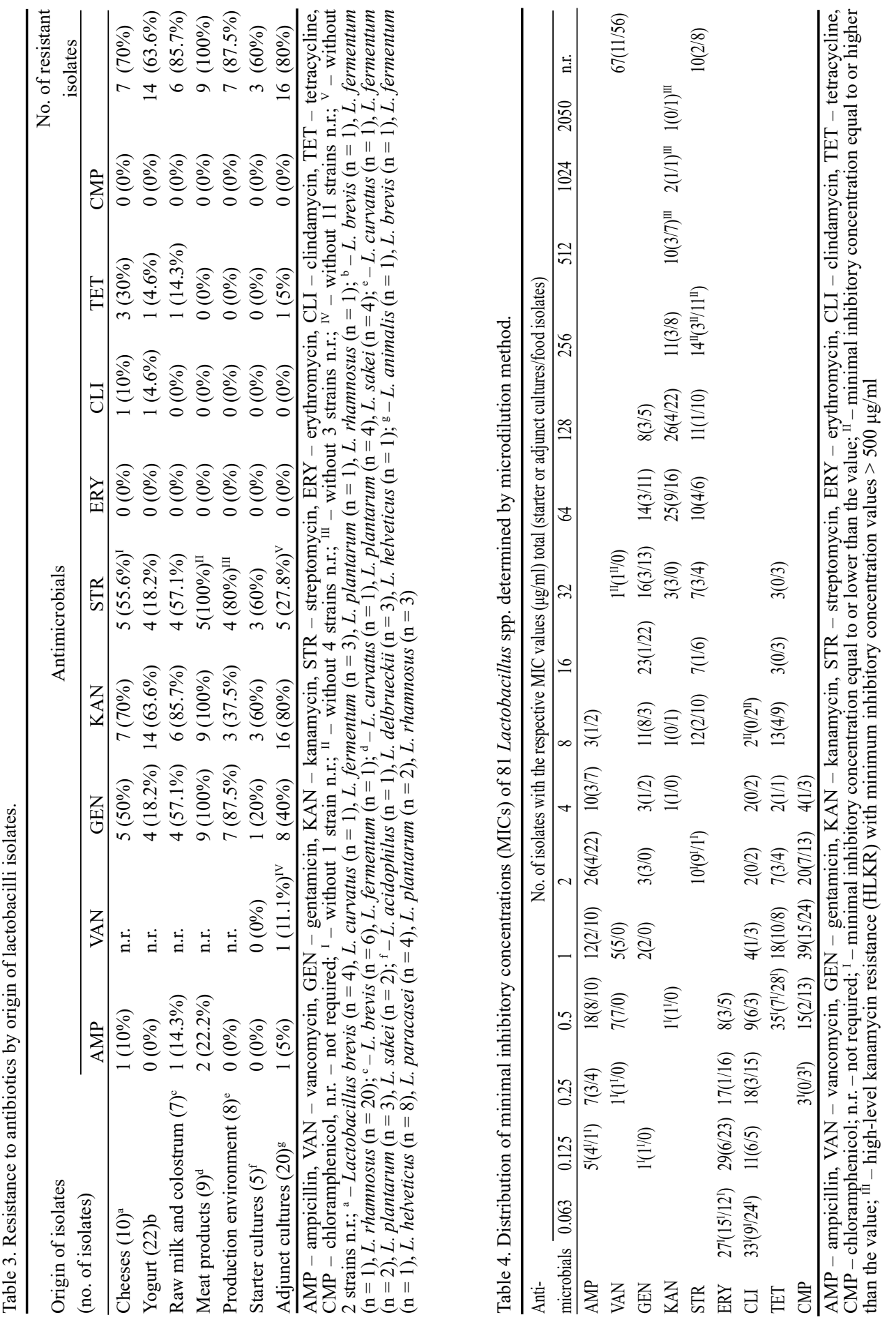


The largest number of resistant strains originated from meat products. Each of these strains was phenotypically resistant to at least one antimicrobial agent. A low percentage of susceptible strains were isolated from the food processing environment $(12.5 \%)$ and from raw milk and colostrum (14.3\%).

Lactobacilli from our study showed high level of kanamycin resistance (HLKR) with minimum inhibitory concentration values $>500 \mu \mathrm{g} / \mathrm{ml}$ in 13 strains (Table 4). Four strains with HLKR originated from adjunct cultures (L. animalis, L. paracasei, L. plantarum), four strains from meat products (L. plantarum), two strains from cheeses (L. brevis, L. fermentum), one strain from the product processing environment (L. plantarum), one strain from goat's milk yogurt (L. brevis) and one strain from raw cow's milk (L. brevis). Lactobacillus brevis from raw cow's milk belongs to non-starter LAB. Other strains with HLKR were either included in the starter and adjunct cultures, or isolated from fermented products and food production environments. High-level gentamicin resistance (HLGR) and high-level streptomycin resistance (HLSR) were not detected in any tested strain.

\section{Discussion}

\section{Phenotypic profiles of antimicrobial resistance}

In our study, resistance to aminoglycosides was detected most frequently. Sixty-two strains $(76.5 \%)$ were resistant to at least one aminoglycoside antibiotic (streptomycin, kanamycin or gentamicin). Increased resistance to aminoglycosides has been described in lactobacilli in a number of other studies (Nawaz et al. 2011; Zhou et al. 2012; Jaimee and Halami 2016; Guo et al. 2017; Li et al. 2019). Nawaz et al. (2011) and Zhou et al. (2012) most often observed resistance to kanamycin in the tested lactobacilli. In our study, resistance to kanamycin was found in $71.6 \%$ of the strains. Curragh and Collins (1992) considered that in most cases, aminoglycoside resistance may be explained by chromosomal mutations. In spite of that, specific genes associated with aminoglycoside resistance have been described in LAB (Ou oba et al. 2008; Zhou et al. 2012). Resistance to erythromycin and tetracycline in lactobacilli is often tested. Both types of resistance are often demonstrated in association with horizontally transmissible erm and tet genes (Nawaz et al. 2011; Devirgiliis et al. 2013). Nawaz et al. (2011) confirmed the transfer of $\operatorname{erm}(\mathrm{B})$ and tet(M) genes from L. fermentum, L. salivarius, L. plantarum and L. brevis to Enterococcus faecalis. Resistance to erythromycin was not detected in our tested strains. Generally, most species of lactobacilli were susceptible to antimicrobials that are able to inhibit protein synthesis (clindamycin, erythromycin, chloramphenicol and tetracycline) (Katla et al. 2001; Ammor et al. 2007; Ammor et al. 2008; Guo et al. 2017; Li et al. 2019). Most studies showed susceptibility of lactobacilli to ampicillin (Nawaz et al. 2011; Georgieva et al. 2015; Guo et al. 2017; Li et al. 2019).

This is in accordance with our study where resistance to ampicillin was demonstrated in only five strains $(6.2 \%)$ and resistance to clindamycin in two strains $(2.5 \%)$. The resistance to chloramphenicol was not detected. Chloramphenicol resistance testing would efficiently cover for the hazard of acquired resistance to linezolid, encoded by the $c f r$ gene, conferring the resistance to chloramphenicol (Toh et al. 2007; Arias et al. 2008; EFSA 2008).

It is recommended to consume foods where lactobacilli are a typical ingredient. Due to the possibility of antibiotic resistance genes transfer from lactobacilli to commensal and pathogenic bacteria in the intestine, the potential risk of spreading resistance increases. Therefore, it is necessary to monitor resistance also in bacteria that are considered to be generally recognized as safe. The isolates with MICs above the cut-off values recommended by the FEEDAP Panel for antibiotics require further investigation to determine the nature of the resistance and to make a distinction between intrinsic and acquired resistance. Presence of acquired resistance on mobile genetic elements poses 
the highest risk of resistance dissemination. The FEEDAP Panel considers not using the strains of bacteria that carry the acquired resistance to antimicrobials as feed additives (EFSA 2012, 2018).

\section{Antimicrobial resistance genes}

Whole genome sequencing should be introduced/used for the detection of genes coding for or contributing to resistance to antibiotics relevant to their use in animals and human. For this purpose, a comparison against up-to-date databases should be performed (EFSA 2018). ResFinder and CARD are web servers providing a user experience way of identifying acquired antibiotic resistance genes on mobile elements in sequenced strains (Zankari et al. 2012; EFSA 2018). The low number of available genome sequences to date are limiting a precise understanding of the origin of phenotypic resistances, either induced or uninduced by the presence of antibiotics (Abriouel et al. 2015).

The aadE gene detected in L. animalis from adjunct culture encodes aminoglycoside O-nucleotidyltransferase ANT(6) which determines resistance to streptomycin (Ramirez and Tolmansky 2010). This gene has already been reported in lactobacilli (Shao et al. 2015; Dec et al. 2017). On the basis of comparison of the observed sequence with the BLAST database (https://blast.ncbi.nlm.nih.gov/Blast.cgi), aadE gene was confirmed, for example, in Streptococcus suis, Staphylococcus aureus, Enterococcus faecium, E. faecalis and L. salivarius. The gene can be found on both the chromosome and the plasmids.

High-level kanamycin resistance (HLKR) and high-level gentamicin resistance (HLGR) with minimum inhibitory concentration values $>500 \mu \mathrm{g} / \mathrm{ml}$ have been associated with the bifunctional $\operatorname{aac}\left(6^{\prime}\right) \mathrm{Ie}-a p h\left(2^{\prime \prime}\right)$ Ia gene (Jaimee and Halami 2016). Although HLKR was found in one L. animalis strain $(1024 \mu \mathrm{g} / \mathrm{ml})$ and one L. brevis strain $(2050 \mu \mathrm{g} / \mathrm{ml})$, this bifunctional gene was not detected in our study. If no known AMR gene linked to the phenotype is detected, no further studies are required (EFSA 2018).

Phenotypic resistance to tetracycline was detected in six strains of two species (L. animalis, L. brevis), out of which four multiresistant strains were analysed by WGS. The tet genes together with $\mathrm{erm}$ genes belong to the most widespread antibiotic resistance determinants in LAB which are commonly associated with horizontal gene transfer. However, based on the analysis by CARD and ResFinder, any known acquired gene determinants for tetracycline resistance were not identified. This discrepancy between phenotypic and molecular analysis may be explained by the results of Egervärn et al. (2009), who observed an association of the occurrence of tet genes in L. reuteri with a certain level of MIC, particularly tet (W) determinants were detected only in strains with MIC over $64 \mu \mathrm{g} / \mathrm{ml}$. In the current study, all strains had MIC under $64 \mu \mathrm{g} / \mathrm{ml}$. The absence of the tet gene in strains with tetracycline resistance may also be caused by other mechanisms such as mutations (Chopra and Roberts 2001). The mechanisms and genetic basis of resistance to certain antimicrobials are still largely unknown in LAB (Li et al. 2019).

The failure of AMR gene transfer in complex gastrointestinal environments indicates the interference from indigenous gut microbiota of the hosts (Feld et al. 2008; Egervärn et al. 2010; Ma et al. 2017). However, it is still not clear whether or not the foodborne lactobacilli worsen the problem of AMR of bacteria in the gastrointestinal tract of human (Ma et al. 2017). Therefore, the public health safety of lactobacilli species should be considered, even though they are commonly present in the indigenous microbiota (the oral cavity, the female genital tract, and the gastrointestinal tract).

\section{Resistance to antibiotics of lactobacilli based on origin of strains}

Although resistance to tetracycline and erythromycin in L. plantarum from cheeses and yogurts has already been described (Nawaz et al. 2011; Zago et al. 2011), our strains of L. plantarum from these commodities were sensitive to both antibiotics. 
In the study of Zonen schain et al. (2009), 75\% of lactobacilli (L. curvatus, L. plantarum and $L$. sakei) isolated from Italian fermented dry sausages were phenotypically resistant to tetracycline, $50 \%$ to erythromycin, and $45 \%$ were resistant to both antibiotics. In our case, any resistance to erythromycin and tetracycline was determined in strains of L. curvatus, L. plantarum, and L. sakei isolated from fermented salami or other meat products.

In animal husbandry, inappropriate use of aminoglycosides has led to the selection of high-level aminoglycoside resistance (HLAR) in LAB (Jaimee and Halami 2016). One hundred percentage of our strains isolated from meat products were resistant to kanamycin, gentamicin and streptomycin. Jaimee and Halami (2016) assessed the presence of aminoglycoside resistant LAB in meat products and farm animals. In their study, lactobacilli isolated from meat products were resistant to kanamycin $(19 \%)$ and gentamicin $(13 \%)$. Thirty-four percent of lactobacilli showed MIC values of $\geq 128 \mu \mathrm{g} / \mathrm{ml}$ for streptomycin. Meat products such as non-fermented sausages were contaminated with aminoglycosideresistant lactobacilli. In our study, even $71 \%$ of samples of meat products (cooked ham, hot smoked dry sausages and fermented salami) and food production environment contained lactobacilli with MIC of $\geq 128 \mu \mathrm{g} / \mathrm{ml}$ for streptomycin.

In conclusion, the results of this study show that starter or adjunct cultures and lactobacilli naturally present in food are resistant to antimicrobials and may act as reservoirs of AMR genes. Due to food consumption, the safety of these bacteria is of high importance as their resistance to antimicrobials can be one of the many potential risks to public health. When resistance to antibiotics is demonstrated in a bacterial strain by the phenotypic method, it is desirable to check the molecular basis of such resistance to determine whether it is intrinsic or acquired. In our study, a horizontally transmissible gene (aadE) was confirmed in L. animalis from an adjunct culture used for fermented dairy products. Horizontal transfer of resistant genes should be tested not only in strains used as starter cultures but also in adjunct cultures. Although Lactobacillus species are not considered as pathogenic bacteria, they occur frequently and in large numbers in food, especially fermented one. This fact may negatively contribute in the spread of genes encoding resistance to antibiotics through the human food chain.

\section{Acknowledgements}

This work was supported by the project of the Ministry of Agriculture NAZV KUS QJ 1510338. We thank Ing. Miloslava Kavková, $\mathrm{PhD}$, for providing the starter strains and Ing. Hana Vlková for her technical assistance in MIC determination.

\section{References}

Abriouel H, Muñoz MDC, Lerma LL, Montoro BP, Bockelmann W, Pichner R, Kabisch J, Cho GS, Franz CMAP, Gálvez A, Benomar N 2015: New insights in antibiotic resistance of Lactobacillus species from fermented foods. Food Res Int 78: 465-481

Ammor MS, Flórez AB, Mayo B 2007: Antibiotic resistance in non-enterococcal lactic acid bacteria and bifidobacteria. Food Microbiol 24: 559-570

Ammor MS, Gueimonde M, Danielsen M, Zagorec M, van Hoek AHAM, de los Reyes-Gavilán CG, Mayo B, Margolles A 2008: Two different tetracycline resistance mechanisms, plasmid-carried tet(1) and chromosomally located transposon-associated tet(M), coexist in Lactobacillus sakei rits 9. Appl Environ Microb 74: 1394-1401

Arias CA, Vallejo M, Reyes J, Panesso D, Moreno J, Castaneda E, Villegas MV, Murray BE, Quinn JP 2008: Clinical and microbiological aspects of linezolid resistance mediated by the $c f r$ gene encoding a $23 \mathrm{~S}$ rRNA methyltransferase. J Clin Microbiol 46: 892-896

Atashpaz S, Khani S, Barzegari A, Barar J, Vahed SZ, Azarbaijani R, Omidi Y 2010: A robust universal method for extraction of genomic DNA from bacterial species. Microbiology 79: 538-542

Bardon J, Mlynarcik P, Prochazkova P, Roderova M, Mezerova K, Kolar M 2018: Occurrence of bacteria with a dangerous extent of antibiotic resistance in poultry in the Central Region of Moravia. Acta Vet Brno 87: 165-172

Bernardeau M, Vernoux JP, Henri-Dubernet S, Guéguen M 2008: Safety assessment of dairy microorganisms. The Lactobacillus genus. Int J Food Microbiol 126: 278-285 
Chopra I, Roberts M 2001: Tetracycline antibiotics: Mode of action, applications, molecular biology, and epidemiology of bacterial resistance. Microbiol Mol Biol R 65: 232-260

CLSI 2016: Methods for antimicrobial dilution and disk susceptibility testing of infrequently isolated or fastidious bacteria ( $3^{\text {rd }}$ edn). CLSI guideline M45, Wayne, PA: Clinical and Laboratory Standards Institute

Curragh HJ, Collins MA 1992: High levels of spontaneous drug resistance in Lactobacillus. J Appl Bacteriol 73: 31-36

Dec M, Urban-Chmiel R, Stepien-Pysniak D, Wernicki A 2017: Assessment of antibiotic susceptibility in Lactobacillus isolates from chickens. Gut Pathog 9: e54

Devirgiliis C, Zinno P, Perozzi G 2013: Update on antibiotic resistance in foodborne Lactobacillus and Lactococcus species. Front Microbiol 4: e00301

Dušková M, Šedo O, Kšicová K, Zdráhal Z, Karpíšková R 2012: Identification of lactobacilli isolated from food by genotypic methods and MALDI-TOF MS. Int J Food Microbiol 159: 107-114

EFSA 2008: Technical guidance prepared by the Panel on Additives and Products or Substances used in Animal Feed (FEEDAP) on the update of the criteria used in the assessment of bacterial resistance to antibiotics of human or veterinary importance. EFSA Journal 732: 1-15

EFSA 2012: EFSA Panel on Additives and Products or Substances used in Animal Feed (FEEDAP); Guidance on the assessment of bacterial susceptibility to antimicrobials of human and veterinary importance. EFSA Journal 2012 10: e02740

EFSA 2018: Guidance on the characterization of microorganisms used as feed additives or as production organisms. EFSA Journal 2018 16: e05206

Egervärn M, Lindmark H, Olsson J, Roos S 2010: Transferability of a tetracycline resistance gene from probiotic Lactobacillus reuteri to bacteria in the gastrointestinal tract of humans. Anton Leeuw Int J G 97: 189-200

Egervärn M, Roos S, Lindmark H 2009: Identification and characterization of antibiotic resistance genes in Lactobacillus reuteri and Lactobacillus plantarum. J Appl Microbiol 107: 1658-1668

Ehrmann MA, Muller MRA, Vogel RF 2003: Molecular analysis of sourdough reveals Lactobacillus mindensis sp nov. Int J Syst Evol Micr 53: 7-13

Feld L, Schjørring S, Hammer K, Licht TR, Danielsen M, Krogfelt K, Wilcks A 2008: Selective pressure affects transfer and establishment of a Lactobacillus plantarum resistance plasmid in the gastrointestinal environment. J Antimicrob Chemoth 61: 845-852

Georgieva R, Yocheva L, Tserovska L, Zhelezova G, Stefanova N, Atanasova A, Danguleva, A, Ivanova G, Karapetkov N, Rumyan N, Karaivanova E 2015: Antimicrobial activity and antibiotic susceptibility of Lactobacillus and Bifidobacterium spp. intended for use as starter and probiotic cultures. Biotechnol Biotec Eq 29: 84-91

Guo H, Pan L, Li L, Lu J, Kwok L, Menghe B, Zhang, H., Zhang W 2017: Characterization of antibiotic resistance genes from Lactobacillus isolated from traditional dairy products. J Food Sci 82: 724-730

Hati S, Mandal S, Prajapati JB 2013: Novel starters for value added fermented dairy products. Curr Res Nutr Food Sci Jour 1: 83-91

ISO10932/IDF223 guideline 2010: Milk and milk products: determination of the minimal inhibitory concentration (MIC) of antibiotics applicable to bifidobacteria and non-enterococal lactic acid bacteria (LAB). International Dairy Federation and International Organization for Standardization: 1-31

Jaimee G, Halami PM 2016: High level aminoglycoside resistance in Enterococcus, Pediococcus and Lactobacillus species from farm animals and commercial meat products. Ann Microbiol 66: 101-110

Katla AK, Kruse H, Johnsen G, Herikstad H 2001: Antimicrobial susceptibility of starter culture bacteria used in Norwegian dairy products. Int J Food Microbiol 67: 147-152

Leroy F, De Vuyst L 2004: Lactic acid bacteria as functional starter cultures for the food fermentation industry. Trends Food Sci Tech 15: 67-78

Li YM, Li LL, Kromann S, Chen MR, Shi L, Meng HC 2019: Antibiotic resistance of Lactobacillus spp. and Streptococcus thermophilus isolated from Chinese fermented milk products. Foodborne Pathog Dis 16: 221-228

Ma Q, Fu Y, Sun H, Huang Y, Li L, Yu Q, Dinnyes A, Sun Q 2017: Antimicrobial resistance of Lactobacillus spp. from fermented foods and human gut. LWT-Food Sci Technol 86: 201-208

Mathur S, Singh R 2005: Antibiotic resistance in food lactic acid bacteria - a review. Int J Food Microbiol 105 : 281-295

McArthur AG, Wright GD 2015: Bioinformatics of antimicrobial resistance in the age of molecular epidemiology. Curr Opin Microbiol 27: 45-50

Nawaz M, Wang J, Zhou A, Ma C, Wu X, Moore JE, Millar BC, Xu J 2011: Characterization and transfer of antibiotic resistance in lactic acid bacteria from fermented food products. Curr Microbiol 62: 1081-1089

Ortigosa M, Arizcun C, Irigoyen A, Oneca M, Torre P 2006: Effect of lactobacillus adjunct cultures on the microbiological and physicochemical characteristics of Roncal-type ewes'-milk cheese. Food Microbiol 23: 591-598

Ouoba LII, Lei V, Jensen LB 2008: Resistance of potential probiotic lactic acid bacteria and bifidobacteria of African and European origin to antimicrobials: Determination and transferability of the resistance genes to other bacteria. Int J Food Microbiol 121: 217-224 
Pavlik I, Horvathova A, Dvorska L, Bartl J, Svastova P, du Maine R, Rychlik I 1999: Standardisation of restriction fragment length polymorphism analysis for Mycobacterium avium subspecies paratuberculosis. J Microbiol Meth 38: $155-167$

Ramirez MS, Tolmasky ME 2010: Aminoglycoside modifying enzymes. Drug Resist Update 13: 151-171

Rossi F, Rizzotti L, Felis GE, Torriani S 2014: Horizontal gene transfer among microorganisms in food: Current knowledge and future perspectives. Food Microbiol 42: 232-243

Shao Y, Zhang W, Guo H, Pan L, Zhang H, Sun T 2015: Comparative studies on antibiotic resistance in Lactobacillus casei and Lactobacillus plantarum. Food Control 50: 250-258

Toh SM, Xiong L, Arias CA, Villegas MV, Lolans K, Quinn J, Mankin AS 2007: Acquisition of a natural resistance gene renders a clinical strain of methicillin-resistant Staphylococcus aureus resistant to the synthetic antibiotic linezolid. Mol Microbiol 64: 1506-1514

Toomey N, Bolton D, Fanning S 2010: Characterisation and transferability of antibiotic resistance genes from lactic acid bacteria isolated from Irish pork and beef abattoirs. Res Microbiol 161: 127-135

Verraes C, Van Boxstael S, Van Meervenne E, Van Coillie E, Butaye P, Catry B, de Schaetzen MA, Van Huffel X, Imberechts H, Dierick K, Daube G, Saegerman C, De Block J, Dewulf J, Herman L 2013: Antimicrobial resistance in the food chain: a review. Int J Env Res Pub He 10: 2643-2669

Wattam AR, Davis JJ, Assaf R, Boisvert S, Brettin T, Bun C, Conrad N, Dietrich EM, Disz T, Gabbard JL, Gerdes S, Henry CS, Kenyon RW, Machi D, Mao C, Nordberg EK, Olsen GJ, Murphy-Olson DE, Olson R, Overbeek R, Parrello B, Pusch GD, Shukla M, Vonstein V, Warren A, Xia F, Yoo H, Stevens RL 2017: Improvements to PATRIC, the all-bacterial Bioinformatics Database and Analysis Resource Center. Nucleic Acids Res 45: D535-D542

Yoon SH, Ha SM, Kwon S, Lim J, Kim Y, Seo H, Chun J 2017: Introducing EzBioCloud: a taxonomically united database of 16S rRNA gene sequences and whole-genome assemblies. Int J Syst Evol Micr 67: 1613-1617

Zago M, Fornasari ME, Carminati D, Burns P, Suàrez V, Vinderola G, Reinheimer J, Giraffa G 2011: Characterization and probiotic potential of Lactobacillus plantarum strains isolated from cheeses. Food Microbiol 28: 1033-1040

Zankari E, Hasman H, Cosentino S, Vestergaard M, Rasmussen S, Lund O, Aarestrup FM, Larsen MV 2012: Identification of acquired antimicrobial resistance genes. J Antimicrob Chemoth 67: 2640-2644

Zhou N, Zhang JX, Fan MT, Wang J, Guo G, Wei XY 2012: Antibiotic resistance of lactic acid bacteria isolated from Chinese yogurts. J Dairy Sci 95: 4775-4783

Zonenschain D, Rebecchi A, Morelli L 2009: Erythromycin- and tetracycline-resistant lactobacilli in Italian fermented dry sausages. J App Microbiol 107: 1559-1568 